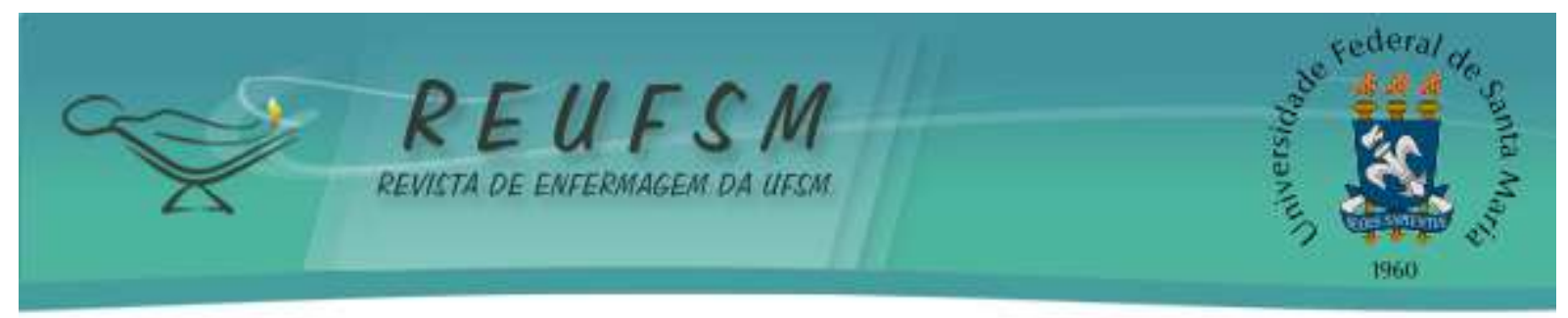

\title{
PASSAGEM DE PLANTÃO COMO FERRAMENTA DE GESTÃO PARA SEGURANÇA DO PACIENTE
}

\section{MEDICAL SHIFTS PASSAGE AS A MANAGEMENT TOOL FOR PATIENT SAFETY \\ PASAJE DE LA GUARDIA COMO HERRAMIENTA DE GESTIÓN PARA LA SEGURIDAD DEL PACIENTE}

Juliana da Silva Garcia Nascimento ${ }^{1}$ Regina Rodovalho Rodrigues ${ }^{2}$

Fabiana Cristina Pires ${ }^{3}$ Bárbara Ferreira Gomes ${ }^{4}$

Doi: $10.5902 / 2179769229412$

RESUMO: Objetivo: compreender o processo de passagem de plantão do enfermeiro e elaborar uma ferramenta para viabilizar cientificamente tal contexto. Método: estudo de abordagem qualitativa, descritivo, realizado com 18 enfermeiros, por entrevistas semiestruturada analisadas por meio da Análise de Conteúdo, de setembro a dezembro de 2016. Para a elaboração do instrumento, foram utilizadas a observação participante e o Método do Arco de Maguerez. Resultados: identificou-se que a passagem de plantão apresenta caráter empírico, evidenciando a ausência de ferramenta científica que qualifique este processo, fragilizando a segurança dos pacientes. Foram detectados nós críticos como: o local da passagem de plantão, interrupções e excesso de comunicação, dessa forma, elaborouse um instrumento em formato de checklist embasado no modelo Situation, Background, Assessment, Recommendation - SBAR de comunicação. Considerações finais: evidencia-se que é possível eliminar o caráter empírico da passagem de plantão utilizando a ferramenta SBAR, favorecendo a segurança dos pacientes.

Descritores: Enfermagem; Comunicação; Segurança; Gestão da qualidade, Hospitais

ABSTRACT: Objective: to understand the nurses' shift process and to develop a tool to scientifically enable such context. Method: a qualitative, descriptive study, carried out with 18 nurses, through semi-structured interviews analyzed by the Content Analysis, from September to December 2016. For the instrument elaboration, participant observation and the Method of the Arch of Maguerez were used. Results: it was identified that the passage of the shift is empirical, evidencing the absence of a scientific tool that qualifies this process, which weakens patient safety. Critical nodes were detected, such as: the location of the shift, interruptions and over-communication, thus, an instrument was developed as a checklist format based on the Situation, Background, Assessment, Recommendation - SBAR model of communication. Final considerations: it is evident that it is possible to eliminate the empirical character of the shift by using the SBAR tool, which benefits patient safety.

Descriptors: Nursing; Communication; Safety; Quality management, Hospitals

\footnotetext{
${ }^{1}$ Enfermeira. Mestre. Universidade de Uberaba, Uberaba, Minas Gerais, Brasil. E-mail: mestradounesp28@yahoo.com.br

${ }^{2}$ Enfermeira.Universidade de Uberaba. Uberaba, Minas Gerais, Brasil. E-mail: reginarrodrigues@msn.com

${ }^{3}$ Enfermeira. Especialista em Urgência e Emergência. Universidade de Uberaba. Uberaba, Minas Gerais, Brasil.

E-mail: enfermagem.pires@gmail.com

${ }^{4}$ Enfermeira.Universidade de Uberaba. Uberaba, Minas Gerais, Brasil. E-mail:

barbaraferreira_2007@hotmail.com
} 


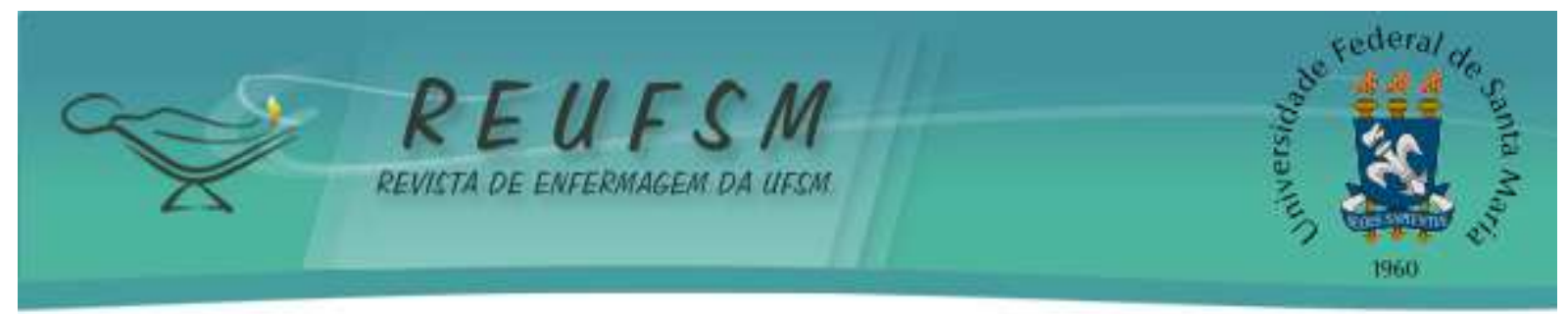

RESUMEN: Objetivo: comprender el proceso de pasaje de guardia del enfermero y elaborar una herramienta para basar científicamente tal contexto. Método: Estudio de perspectiva cualitativa, descriptiva, realizado con 18 enfermeros, por medio de entrevistas semiestructuradas analizadas a partir del Análisis de Contenido, entre septiembre y diciembre de 2016. Para la elaboración del instrumento, se utilizó la observación participante y el Método del Arco de Maguerez. Resultados: se identificó que el pasaje de la guardia presenta carácter empírico, lo que evidencia la ausencia de una herramienta científica que califique ese proceso, debilitando la seguridad de los pacientes. Se detectó nudos críticos como: el lugar de pasaje de guardia, interrupciones y exceso de comunicación, a partir de esas constataciones, se elaboró un instrumento en formato de checklist basado en el modelo Situation, Background, Assessment, Recommendation - SBAR de comunicación. Consideraciones finales: se evidencia que es posible eliminar el carácter empírico del pasaje de guardia utilizando la herramienta SBAR, favoreciendo la seguridad de los pacientes.

Descriptores: Enfermería; Comunicación; Seguridad; Gestión de la calidad, Hospitales

\section{INTRODUÇÃO}

A segurança do paciente na atualidade é foco de discussão, visualizada em âmbito nacional e internacional, principalmente pela sua importância para o sistema de saúde e as repercussões na sociedade em geral. ${ }^{1}$

Em 2004, na 57ª Assembleia Mundial da Saúde, foi criada a Aliança Mundial para a Segurança do Paciente, objetivando facilitar o desenvolvimento de práticas e políticas de segurança em diversos países, por meio de programas e disseminação de seis principais metas internacionais, dentre as quais, destaca-se a meta dois, que concerne à melhora da comunicação efetiva entre os profissionais da saúde. ${ }^{2}$

Estudos relacionados à segurança do paciente e participação do enfermeiro na implantação de estratégias para melhorar a comunicação no ambiente hospitalar são necessários e recentes. Podem auxiliar os profissionais da área a conhecer as causas e os efeitos das lacunas de comunicação ocorridas, possibilitando treinamentos adequados à prevenção de novas ocorrências e implementação de ferramentas que subsidiem esta intenção. ${ }^{3}$

A comunicação é o elemento essencial do cuidado, principalmente nos processos que envolvem a saúde hospitalar e, quando ineficiente, está entre $70 \%$ dos erros causados durante a assistência. ${ }^{4}$ No processo de trabalho da enfermagem o mecanismo utilizado para a realização da transmissão de informações é denominado 'passagem de plantão'.

A passagem de plantão procura estabelecer comunicação objetiva e clara, a respeito das intercorrências com os pacientes, além dos assuntos referentes à gestão em enfermagem, sendo geralmente subsidiada por protocolos que organizam este processo e proporcionam segurança. ${ }^{6}$ 


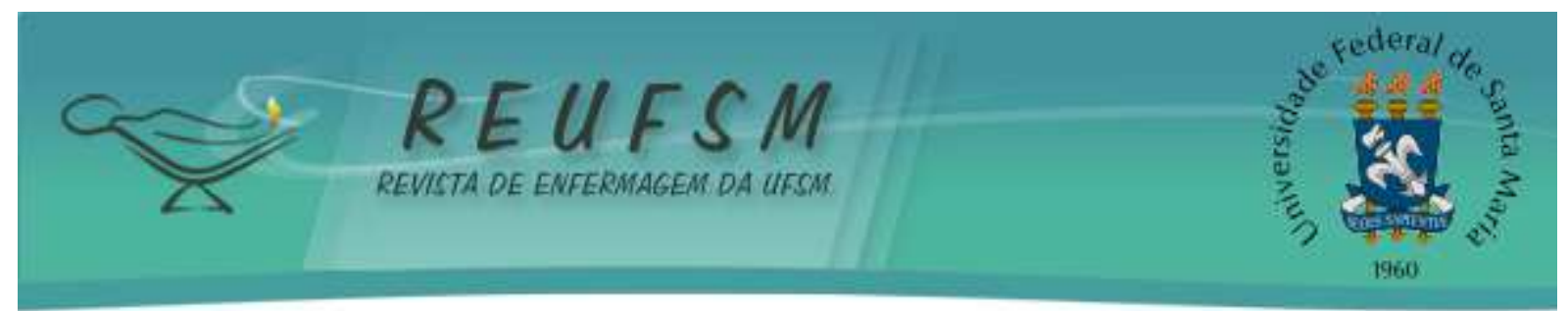

Diversos métodos podem ser adotados para estabelecer a passagem de plantão, porém o mais comum, é a comunicação verbal realizada face a face. ${ }^{6}$ Este formato pode ser considerado insuficiente, quando utilizado de forma exclusiva, comprometendo a segurança da clientela e indicando a necessidade de ferramentas que organizem e registrem porescrito as informações relevantes para a continuidade da assistência. ${ }^{7}$

Uma equipe norte-americana do Institute for Healthcare Improvement desenvolveu, no ano de 2007, a técnica de comunicação denominada Situation, Background, Assessment, Recommendation (SBAR), buscando redesenhar a comunicação em saúde e objetivando um sistema isento de erros, desperdícios, atrasos e com custos sustentáveis. ${ }^{7-9}$

Considerada como ferramenta de gestão, a SBAR é recomendada para organizar o processo de passagem de plantão, consistindo em técnica estruturada, clara e precisa de fornecimento e registro de informações, por meio de quatro questões. ${ }^{10}$ A primeira aponta o que está acontecendo no momento atual com o paciente (Situation); a segunda descreve quais situações levaram àquele momento (Background); a terceira menciona a opinião do profissional sobre o problema (Assessment); e a quarta remete ao que poderia ser feito para corrigir os problemas identificados (Recommendation). ${ }^{7,11}$

A utilização do SBAR proporciona reflexão no processo de passagem de plantão, pela utilização desta sequência de questões consideradas relevantes para a continuidade da assistência em enfermagem, auxiliando no trabalho do profissional, evitando o esquecimento e prevendo uma sequência de informações, ao dar seguimento a este instrumento. ${ }^{11}$

Apesar da existência de métodos científicos, como o SBAR, para a promoção da comunicação eficaz na saúde, tem-se presenciado na prática, passagens de plantão desorganizadas, que dificultam assegurar a excelência do cuidado. ${ }^{7}$

Uma passagem de plantão, mal registrada, pode interferir na segurança dos pacientes, ocasionando perda de informações importantes para a qualidade e a continuidade da assistência de enfermagem, como por exemplo: a não realização de exames, administração de medicamentos, avaliações multiprofissionais e atendimento de outras necessidades humanas básicas. ${ }^{10}$ A ferramenta SBAR pode evitar que tais lacunas aconteçam ou sejam exacerbadas, ao facilitar a troca de informações, estruturar e organizar a comunicação entre a equipe de enfermagem, ${ }^{9-11}$ justificando a realização do presente estudo. 


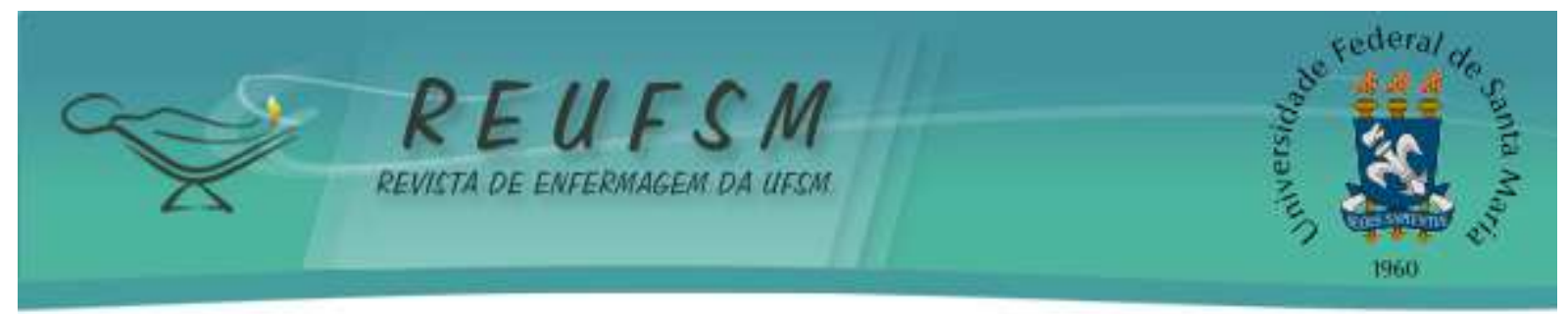

Nesta perspectiva, coube levantar os seguintes questionamentos: como se configura o processo de passagem de plantão dos enfermeiros em ambiente hospitalar? Quais as dificuldades, lacunas ou nós críticos responsáveis pelos ruídos nesta comunicação e pelas inconformidades na segurança do paciente? Os enfermeiros percebem a relação da passagem de plantão com a segurança dos pacientes? Assim, objetivou-se compreender o processo de passagem de plantão do enfermeiro e elaborar uma ferramenta para viabilizar cientificamente tal contexto.

\section{MÉTODO}

Estudo descritivo, exploratório, de caráter qualitativo, realizado em um hospital de grande porte do interior de Minas Gerais, Brasil, com 230 leitos ativos, no período de setembro a dezembro de 2016. A primeira etapa incluiu setores destinados a internar pacientes adultos: Clínica Médica, Clínica Cirúrgica, Unidade de Terapia Intensiva e Maternidade.

A segunda etapa foi contemplada apenas no setor de maternidade, possuindo 30 leitos ativos, deliberada a elaboração da ferramenta proposta, devido à intencionalidade dos enfermeiros gestores em utilizar esta unidade como um projeto piloto no hospital, afim da alteração do processo de passagem de plantão. Cabe esclarecer que a forma de passagem de plantão dos enfermeiros assistenciais neste setor não era embasada em ferramentas científicas, inexistindo seguimento de um padrão para esclarecimento, transmissão e registro das informações pertinentes a segurança do paciente.

Foram utilizados como critérios de inclusão: exercer a função de enfermeiro assistencial, pertencer aos setores citados, participar efetivamente do processo de passagem de plantão. Os critérios de exclusão foram: estar de férias ou licença, independente do motivo, enfermeiros gestores que não realizassem a passagem de plantão comumente, desta forma, foram excluídos quatro enfermeiros gestores e dois enfermeiros que se encontravam de férias no período da coleta.

Inicialmente a população era representada por 24 enfermeiros, após exclusão de 6 profissionais, permaneceram 18 participantes, cinco da Clínica Médica, quatro da Clínica Cirúrgica, quatro da Unidade de Terapia Intensiva, cinco da maternidade. A amostra foi definida em última instancia pelo critério de saturação dos dados presente na pesquisa qualitativa. ${ }^{12}$

Foram utilizados dois instrumentos para coleta de dados elaborado pelos autores do estudo. Primeiramente um roteiro com perguntas norteadoras, dividido em dois domínios. O primeiro caracterizou os enfermeiros abordando: sexo; faixa etária; tempo de atuação na 


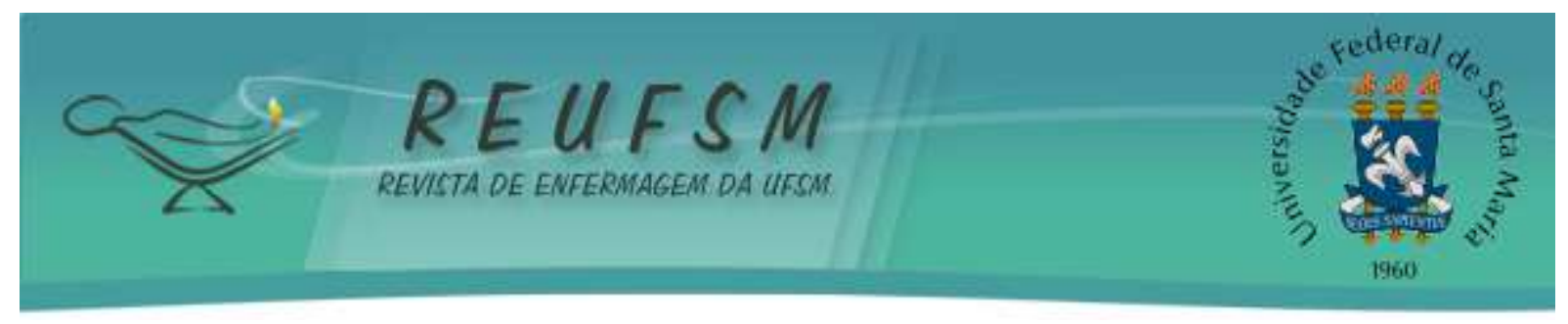

instituição; e participação em curso de atualização ou outra abordagem educativa sobre segurança do paciente. O segundo domínio foi composto por três questões incluindo: a descrição da vivenciado processo de passagem de plantão; as dificuldades encontradas pelos enfermeiros para proceder à passagem de plantão e a relação da passagem de plantão com a segurança do paciente na percepção do participante.

O segundo instrumento buscou organizar a coleta de dados no setor da Maternidade e subsidiar a adaptação da ferramenta SBAR, ${ }^{7-9,11}$ proposta neste estudo, realizado em duas etapas. A primeira: identificação dos critérios abordados na passagem de plantão dos enfermeiros, quanto à puérperas e recém-nascidos; a segunda: levantamento dos pontos-chave e lacunas na passagem de plantão.

A coleta de dados foi constituída por dois momentos. O primeiro abordou às concepções e experiências dos enfermeiros sobre o processo de passagem de plantão por meio de entrevista semiestruturada gravada, seguindo o primeiro instrumento descrito. No momento seguinte, procedeu-se a coleta dos dados pertinentes à adaptação da ferramenta $\mathrm{SBAR}^{7-9,11}$ para passagem de plantão na maternidade, utilizando o segundo instrumento citado nesta pesquisa. Para cumprimento desta etapa, foram acompanhados pelos pesquisadores 46 passagens de plantão nos turnos da manhã, tarde e noite, no mesmo período da realização das entrevistas, por meio da Observação Participante. ${ }^{13}$

A Observação Participante representa uma técnica pela qual se chega ao conhecimento da vida de um grupo, a partir de seu interior, objetivando investigar uma situação. ${ }^{13}$ Os dados coletados foram organizados utilizando como referencial metodológico o Arco de Charles Maguerez. ${ }^{14} \mathrm{O}$ Arco de Maguerez possui cinco etapas que propõem a resolução de problemas na saúde, a saber: (1) observação da realidade; (2) pontos-chave, ambos realizados no segundo momento da coleta; (3) teorização; (4) hipóteses de solução, neste estudo, utilizando a ferramenta SBAR como referencial para solucionar as lacunas vivenciadas; (5) aplicação à realidade. ${ }^{14}$ Ressalta-se que, nesta pesquisa não foi abordada apenas a quinta etapa do arco.

A análise do material obtido emergido das entrevistas e da coleta no setor de maternidade, foi embasada em princípios de interpretação qualitativa de dados, denominada Análise de Conteúdo, procedendo a categorização, organização e análise dos temas evidenciados. ${ }^{12}$

Os participantes foram consultados quanto ao interesse e disponibilidade, e assinaram o Termo de Consentimento Livre e Esclarecido, sendo informados de todas as peculiaridades da 


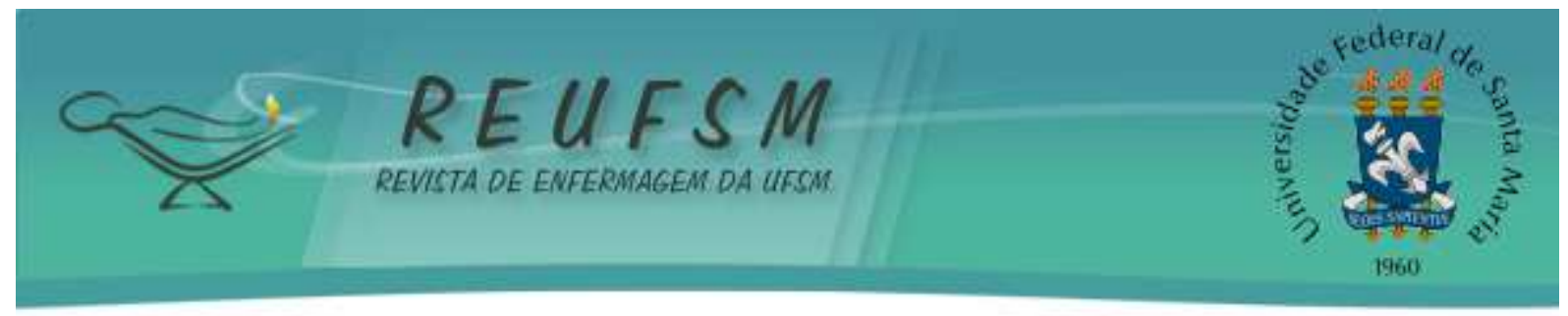

pesquisa. Cabe ressaltar que foi garantido o caráter confidencial e voluntário da participação, bem como o compromisso de mantê-lo na divulgação dos resultados do trabalho. Os procedimentos éticos foram respeitados, e após a aprovação do hospital, o projeto foi encaminhado para o Comitê de Ética cumprindo as exigências da Resolução 466/12 do Conselho Nacional de Saúde, número de parecer 1.748.996.

\section{RESULTADOS E DISCUSSÃO}

Dos participantes do estudo, 16 eram do sexo feminino e dois do sexo masculino, com faixa etária prevalente de 25 a 40 anos, apresentando como menor tempo de atuação no hospital um ano, e o maior tempo relatado foi dez anos, destes, cinco profissionais citaram possuir especialização com ênfase em gestão dos serviços hospitalares.

Da análise dos dados emergiram três unidades temáticas: o caráter empírico da passagem de plantão; os nós críticos da passagem de plantão e a passagem de plantão como estratégia de segurança do paciente.

\section{O caráter empírico da passagem de plantão}

Esta unidade temática foi caracterizada pelo apontamento dos enfermeiros, sobre a ausência de uma ferramenta científica para organização da passagem de plantão, a fim de padronizar este processo.

Em minha passagem de plantão eu sigo apenas as minhas anotações quanto à intercorrências ocorridas durante o plantão, eu sigo a minha forma de fazêelo, não há uma padronização, nem entre os enfermeiros do meu setor, e nem entre o hospital. (E13)

Não tem um protocolo exato para passar plantão, anotamos as intercorrências e pendências no que chamamos de senso, no sistema, após isso, este senso é impresso e com ele eu vou me lembrando destes detalhes e passando para o colega que chega para passar plantão. (E2)

Recomenda-se a utilização de ferramentas científicas para registro escrito das informações do dia trabalhado, que possibilitem a continuidade da assistência e favoreçam a segurança dos pacientes. ${ }^{10}$ Corroborando com este apontamento, uma pesquisa realizada em hospital universitário no sul do Brasil evidenciou que a passagem de plantão deve ser sistematizada, apresentando padronização das informações e viabilizada por um instrumento que contribua para segurança da clientela. ${ }^{5}$ 


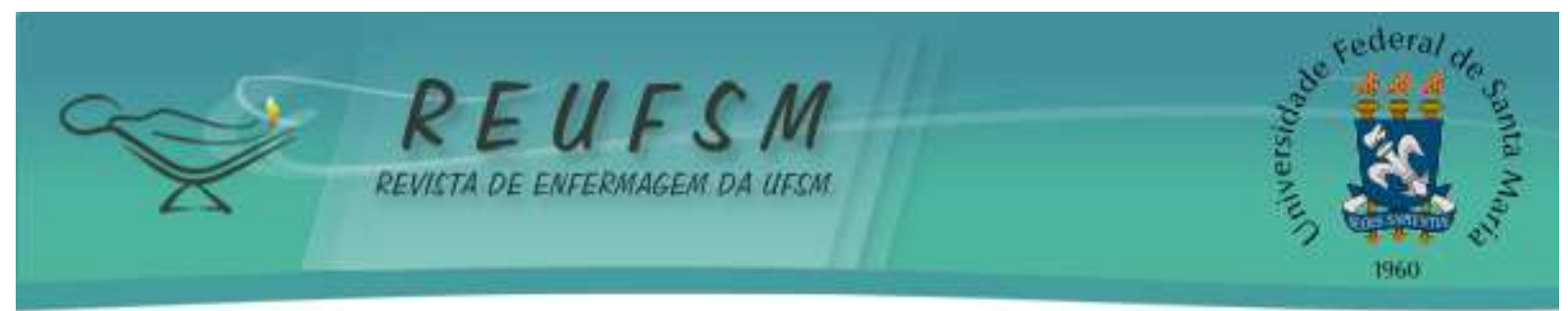

A SBAR é indicada pela literatura como uma ferramenta que organiza as informações, qualificando o processo de passagem de plantão por fornecer sustentação para a comunicação entre profissionais. Este instrumento apresenta a condição clínica do paciente, permite antecipação de condutas, continuidade da assistência e um caráter científico ao processo. ${ }^{9,11}$ Portanto, a aquisição desta ferramenta viabiliza melhora da comunicação e compreensão da assistência prestada aos pacientes, eliminando o caráter empírico. ${ }^{15}$ Reduzindo o fosso entre a teoria e a prática clínica, organizando informações e recomendações, proporcionando assim, segurança a assistência prestada. ${ }^{7,15-17}$

Observou-se, que há a percepção do caráter empírico, na passagem de plantão pelos participantes, que realizam esta prática baseando-se em conhecimentos e vivências, e não seguem um protocolo, caracterizando a necessidade de um instrumento que padronize e organize a comunicação na intencionalidade de qualificar este processo.

\section{Os nós críticos da passagem de plantão}

Foram evidenciadas três principais lacunas no processo de passagem de plantão do profissional enfermeiro no ambiente hospitalar: o local da passagem de plantão, as interrupções durante este momento, e o volume e excesso de comunicação.

O local, considerado inadequado para passagem de plantão na percepção dos enfermeiros, foi caracterizado nas falas a seguir.

A maior dificuldade no meu setor na passagem de plantão é não estar entrando de quarto em quarto para observar e verificar as condições atuais e exatas do paciente. Esta é uma das maiores lacunas para mim, ver a passagem de plantão realizada no balcão do posto de enfermagem. (E4)

Eu acho que o que faltaria é ir à beira do leito, passar o plantão à beira do leito, eu acho que ficaria mais fidedigno assim a passagem de plantão. (E10)

Estudo descritivo e transversal realizado em unidade de terapia intensiva adulto evidenciou que a passagem de plantão pode ser realizada de quatro formas: verbal e distante do paciente, escrita, fita gravada ou comunicada na cabeceira do leito, porém, ressaltou-se que estar à beira do leito proporciona melhor visão do cenário proposto e pode garantir a continuidade do cuidado e a segurança dos pacientes. ${ }^{18}$ 


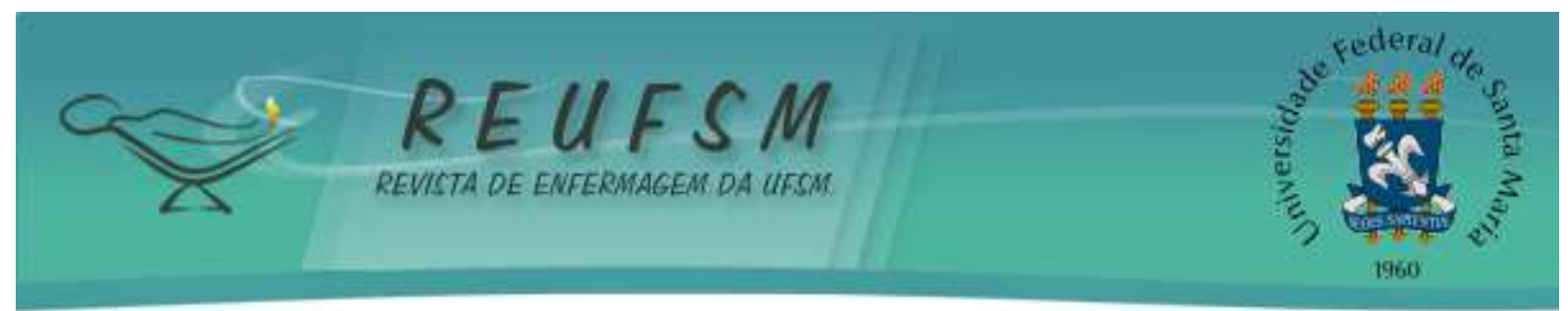

Corroborando com estes dados, uma pesquisa de revisão bibliográfica afirma que, a passagem de plantão é um procedimento primordial no trabalho do enfermeiro, e quando realizada à beira do leito, proporciona coleta de informações sobre o paciente em tempo real, visão holística do estado clínico e aproximação entre os envolvidos, acelerando tomada de decisão e humanizando a assistência. ${ }^{19}$

Outro nó crítico destacado pelos participantes na passagem de plantão foi a interrupção frequente durante esta prática.

A interrupção frequente é um dos principais motivos que dificulta essa passagem para mim, como, por exemplo, paciente chamando, telefone tocando, outros profissionais interferindo, isso desqualifica a passagem de plantão, tira a minha atenção e causa erros. (E3)

Um dos pontos negativos na passagem de plantão é a interferência dos acompanhantes, técnicos de enfermagem e médicos na hora dessa passagem de plantão e telefone tocando durante toda a passagem, querer transferir o paciente durante a passagem, ou você faz uma coisa ou outra, se não, nenhuma atividade terá qualidade. (E5)

Os achados de uma revisão bibliográfica revelaram que o ambiente impróprio, a falta de planejamento e de padronização, o excesso de atribuições para um único enfermeiro, pessoas transitando no espaço destinado à troca de plantão, chamadas telefônicas e o barulho excessivo nas unidades são fatores que comprometem a realização da passagem de plantão. ${ }^{20}$ Ruídos ou interferências podem traduzir-se em falhas nas informações transmitidas e/ou recebidas, ${ }^{21}$ desta forma, alternativas e estratégias são propostas, na tentativa de reduzir as interferências, como a utilização de uma placa que sinalize a não interrupção durante este momento. ${ }^{22}$

Nesta perspectiva, o volume e excesso de comunicação também foram destacados como lacunas que interferem negativamente na qualidade desta ação, evidenciadas nos discursos.

A equipe de enfermagem deveria passar o plantão com mais atenção $e$ responsabilidade, sem conversas paralelas durante o mesmo, pois dificulta a passagem de plantão, distrai, interfere na segurança dos pacientes. (E3)

Meu Deus! Muito barulho, muita gente chegando e saindo, e falando coisas desnecessárias, ou falando muito alto, isso desconcentra, prejudica a passagem de plantão. (E7)

Pesquisa descritiva-exploratória, de abordagem quantitativa, realizado em três unidades de cuidados intensivos neonatais, demonstrou que as conversas paralelas podem interferir na 


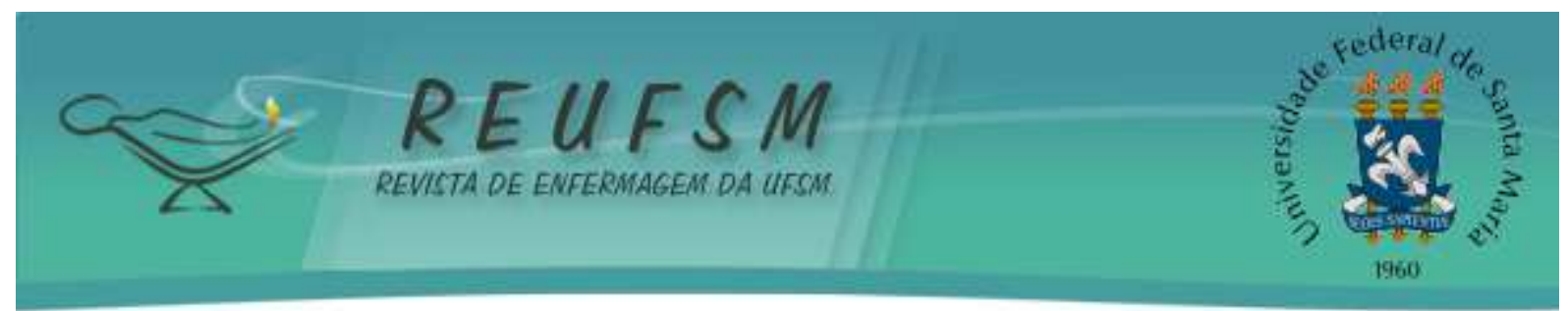

qualidade da passagem de plantão, ocasionando esquecimento ou repasse de informações errôneas e, causam menor retenção das informações. ${ }^{3}$

A passagem de plantão da equipe de enfermagem é ruidosa, contatando-se sons que abarcam 55,2a 75,7 dBA, valores considerados acima das recomendações internacionais e nacionais para ambientes hospitalares. ${ }^{22}$

Desta maneira, evidencia-se um cenário passível de aperfeiçoamento indo ao encontro da percepção dos participantes, englobando estratégias e treinamentos que sensibilizem sobre a relevância de padronizar o local, que evite as interrupções e reduza ou minimize o volume e excesso de comunicação durante a passagem de plantão.

\section{A passagem de plantão como estratégia de segurança do paciente}

Os depoimentos a seguir, deixam transparecer a relação da passagem de plantão como estratégia de segurança do paciente na perspectiva dos enfermeiros.

Sim, a passagem de plantão favorece a segurança da clientela, pois neste momento conseguimos ter uma visão ampla do estado geral, saber como está esse paciente, as necessidades, quais intercorrências aconteceram no plantão anterior para prevenir que não ocorram mais, mas ainda seria preciso obter uma planilha, ou instrumento para organizar estas informações. (E5)

Pela passagem de plantão consigo identificar qual paciente necessita de mais atenção e qual está mais complexo em relação a gravidade. Estes itens interferem diretamente na segurança do paciente se não houver uma boa passagem de plantão que os identifique. (E10)

A comunicação entre as equipes de enfermagem acontece frequentemente, entretanto, a mais importante envolve a passagem de plantão, pois integra a rotina, sendo inerente ao cotidiano da prática da enfermagem. Por meio desta pratica é possível conhecer todas as questões relacionadas ao paciente e sua condição de hospitalizado, gerenciando e prevenindo falhas, configurando-se como mecanismo de segurança assistencial. ${ }^{19}$

A passagem de plantão implica na segurança do paciente, quando as informações são negligenciadas pela equipe durante este processo, por falhas na comunicação, relacionadas a administração de medicamentos, passagem de nomes errados, uso de drogas vasoativas, presença de dreno e muitos outros fatores, interferem negativamente na qualidade do cuidadoprestado. $^{18}$ 


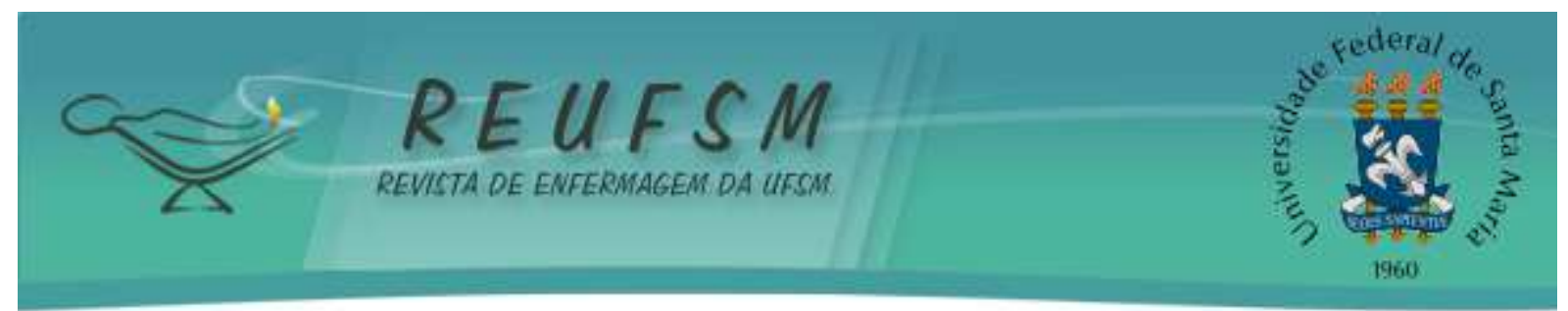

Estudo realizado em três Unidades de Cuidados Intensivos do Sul do Brasil,de 2012 a 2014, constatou comportamentos não benéficos à segurança do paciente. Estas condutas envolviam conversas paralelas e que apesar de existir o reconhecimento da importância da comunicação efetiva na passagem de plantão, algumas práticas mostraram-se frágeis, evidenciando as mudanças como necessárias para garantir segurança e nortear as práticas de cuidados realizadas. ${ }^{23}$

Corroborando com esta informação, pesquisa realizada em um hospital público de Santa Catarina envolvendo 55 enfermeiros concluiu que, a comunicação na passagem de plantão é percebida como essencial ao planejamento do cuidado e que subsidia-la com checklist que contemple todos os itens necessários à segurança deste processo poderá facilitar este desafio. ${ }^{24}$

A ferramenta SBAR é facilitadora da passagem de plantão e proporciona segurança à clientela hospitalizada. Ao contemplar as informações mais relevantes para a continuidade do cuidado, identifica de forma organizada e sistemática o paciente e o motivo de sua internação, informa o histórico, medicamentos em uso, alergias, resultado de exames relevantes, sinais vitais, impressões clínicas, alterações de exame físico, presença de dispositivos, precauções, exames complementares e específico, além de outras recomendações, contemplando os dados importantes que envolvem este processo. ${ }^{5}$

Compreende-se que, a passagem de plantão pode ser considerada um mecanismo que proporciona a segurança dos pacientes, desde que facilitada por instrumentos que padronizem e qualifiquem este processo.

\section{Elaboração de um instrumento de passagem de plantão subsidiado pela ferramenta SBAR, de acordo com o referencial do Arco de Maguerez}

As análises dos achados revelaram a ausência de caráter científico na a passagem de plantão, sendo realizada de acordo com as experiências e vivências de cada enfermeiro. Existem lacunas neste processo que indicam necessidade de ajustes por profissionais e instituição, ocorrendo articulação entre passagem de plantão e a segurança do paciente na percepção dos participantes. Nesta perspectiva, havendo evidências na literatura de que a ferramenta SBAR pode qualificar e organizar este processo, ${ }^{3,7,9,15}$ o setor de maternidade foi selecionado para sediar a elaboração de um instrumento que contemplasse critérios para subsidiar este contexto, devido a ausência de padronização desta prática. 


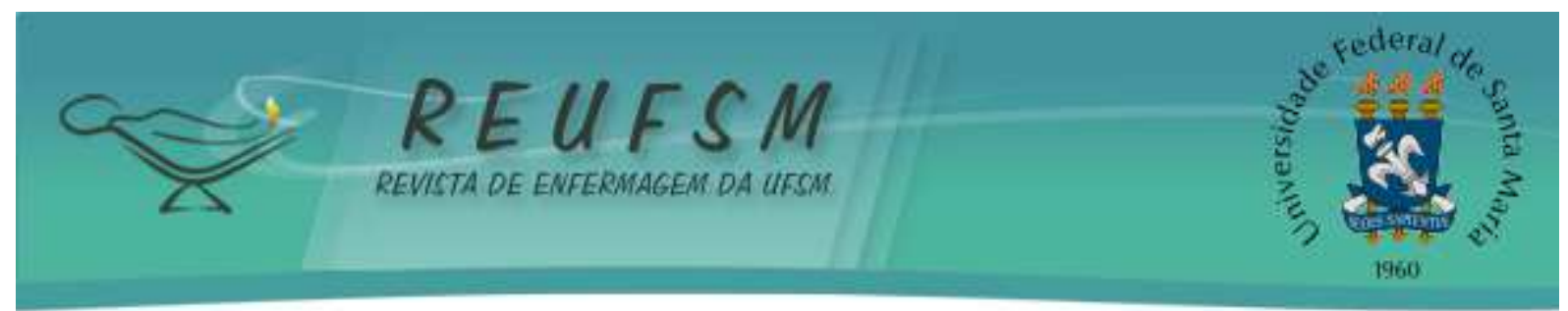

A construção do instrumento para passagem de plantão foi realizada e descrita tendo como referencial as quatro primeiras etapas do Arco de Maguerez. ${ }^{14,25}$

\section{Fase 1. Observação da realidade}

A etapa do Arco de Maguerez, denominada Observação da Realidade, foi realizada por meio da identificação dos cuidados prestados na maternidade ao binômio mãe e filho e dos itens relevantes para a continuidade da assistência, utilizando como método de coleta de dados, a observação participante da realidade. ${ }^{13}$

Foram acompanhadas 46 passagens de plantão na maternidade, durante os turnos da manhã, tarde e noite. Identificou-se 41critérios abordados na passagem de plantão dos enfermeiros, referente as puérperas e recém-nascidos. Estes critérios foram destacados por serem priorizados pelos enfermeiros em todas as passagens de plantão vivenciadas, destes: 20 itens referentes a passagem de plantão das puérperas e 21 itens que caracterizaram a comunicação sobre o recém-nascido, evidenciado na Figura 1.

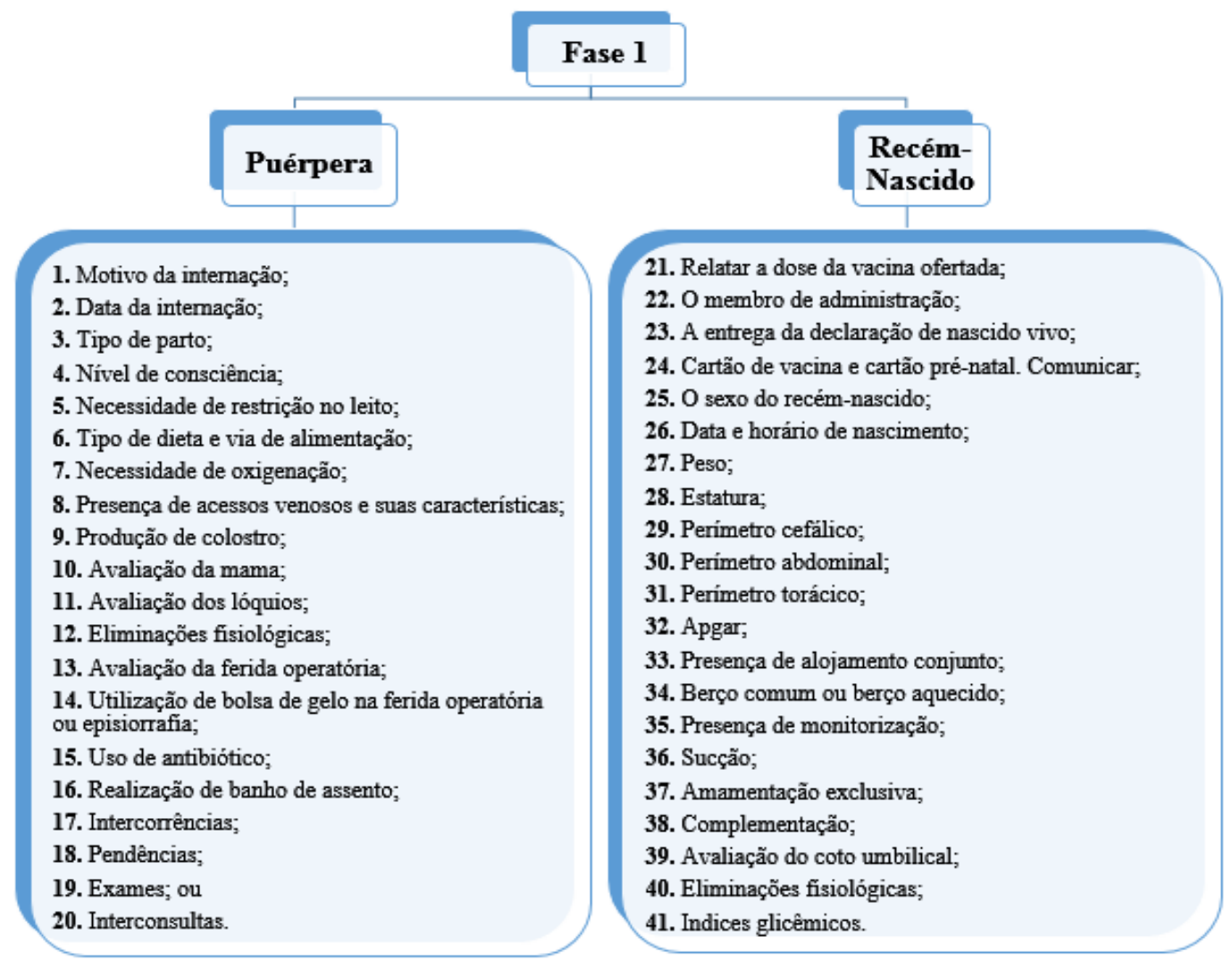

Figura 1 - Identificação dos itens pertinentes à passagem de plantão de puérperas e recém-nascidos no setor de maternidade, levantados durante Observação Participativa da passagem de plantão. Uberaba, 2016 


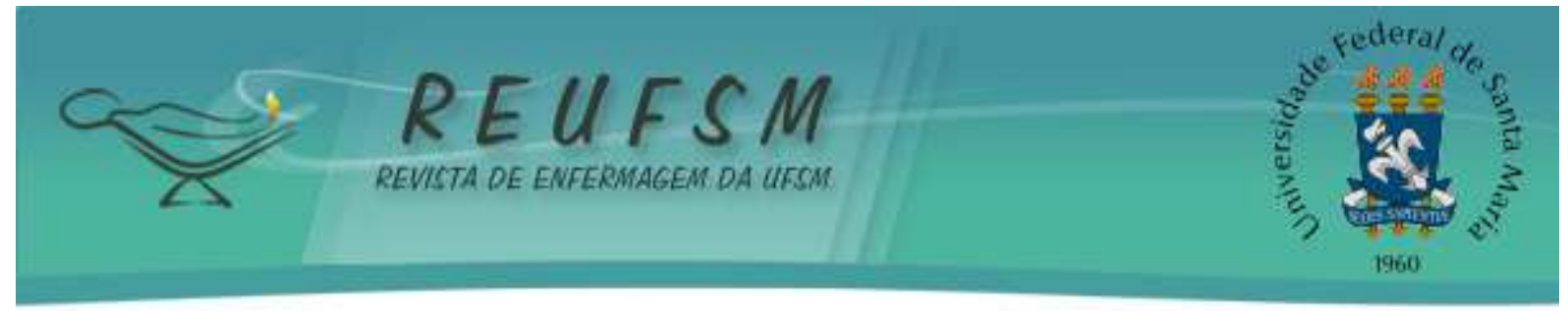

Fase 2. Delineamento dos pontos-chave e lacunas na passagem de plantão

A segunda etapa do Arco de Maguerez para construção da ferramenta de passagem de plantão, contemplou a análise dos itens identificados durante o processo de Observação Participativa, considerando os 41 itens como pontos-chave, caracterizando-os como essenciais para a continuidade da assistência. Constataram-se também nesta fase, os critérios que não foram citados em todas as passagens de plantão pelos enfermeiros, sendo apontados como lacunas do processo, por representarem itens importantes para a manutenção da segurança. Destacam-se nove critérios relacionados a assistência e estado clínico do recém-nascido, observados na Figura 2.

\section{Fase 2}

\section{Lacunas}

1. Falha na comunicação sobre a produção de colostro;

2. Ausência de comunicação do tipo de mamilo para a amamentação;

3. Ausência de comunicação do peso do recém-nascido;

4. Ausência de comunicação da glicemia do recém-nascido;

5. Ausência de comunicação de pendências como a necessidade de realizar exames e interconsultas;

6. Falhas na comunicação quanto a sucção do recém-nascido;

7. Falhas na comunicação sobre a utilização de complementação;

8. Lacunas da comunicação quanto as eliminações fisiológicas do recém-nascido;

9. Falhas evidenciadas na comunicação sobre a administração de vacina de hepatite $B$.

Figura 2 - Lacunas evidenciadas na passagem de plantão do recém-nascido no setor de maternidade. Uberaba, 2016.

Fase 3 e fase 4. Teorização com embasamento da ferramenta SBAR e elaboração do instrumento.

A fase três denominada Teorização e a fase quatro, chamada de Hipótese de Solução foram realizadas simultaneamente. Para a Teorização foi utilizada a ferramenta SBAR na perspectiva da comunicação como referencial teórico. A Hipótese de Solução, para qualificação da passagem de plantão na maternidade foi a elaboração de um instrumento baseado no SBAR para condução e organização deste processo. Este foi dividido em duas partes. A primeira abordando as caraterísticas da passagem de plantão pertinentes à puérpera e a segunda ao recém-nascido, ambas contemplando as quatro fases de comunicação do SBAR. 


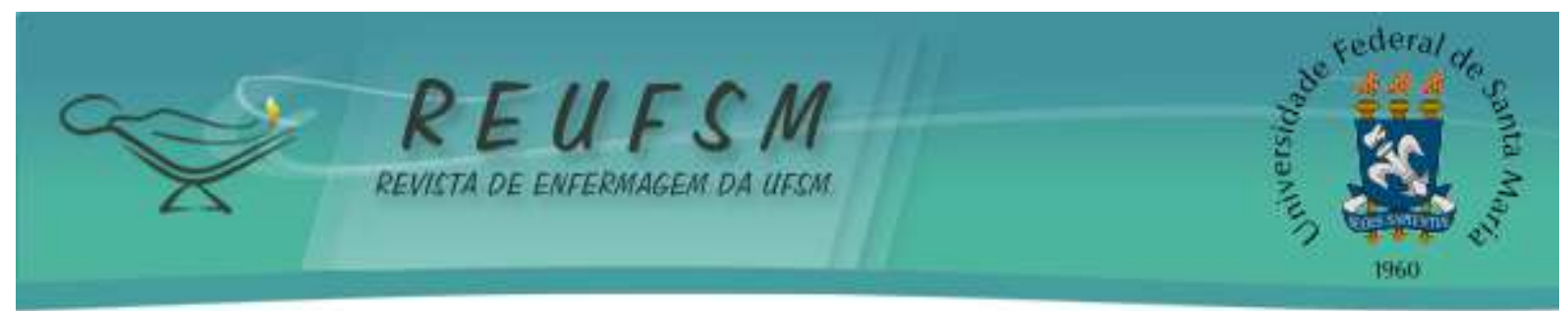

A primeira fase do SBAR, denominada Situação (Situation), corresponde a etapa do instrumento destinado à descrição concisa do motivo de internação, tipo de parto e data atual. A segunda etapa, denominada Quadro Atual (Background), engloba os critérios que devem ser abordados durante a passagem de plantão de puérperas e recém-nascidos, estruturado de acordo coma Observação Participante realizada anteriormente. A terceira etapa, chamada de Avaliação Profissional (Assessment), é o local para descrição da opinião do profissional sobre o contexto da puérpera e recém-nascido, abordando gravidade e intercorrências. A quarta e última etapa caracterizou as Recomendações (Recommendation), isto é, o que pode ser feito para corrigir os problemas e a descrição das pendências, recomendações à puérpera e recémnascido. As quatro etapas podem ser visualizadas na Figura 3.

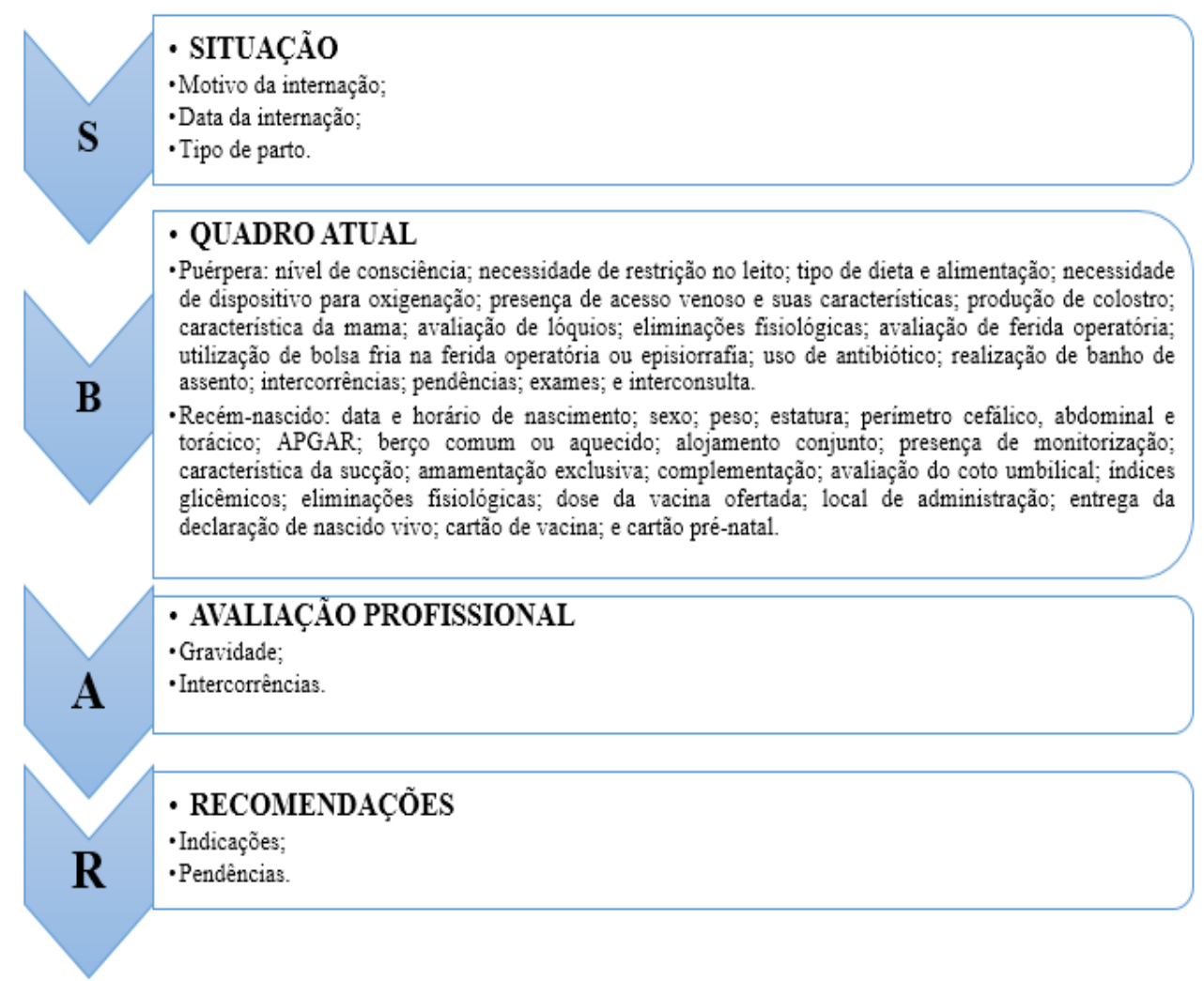

Figura 3 - Organização dos critérios pertinentes a passagem de plantão de puérperas e recém-nascidos com a utilização das etapas do Arco de Maguerez. Uberaba, 2016.

A Figura 3 representa um guia elaborado na intencionalidade de organizar e qualificar o processo de passagem de plantão, utilizando o setor de maternidade com teste piloto. A análise dos achados, identificados durante a Observação Participativa e as percepções que emergiram das falas dos participantes, possibilitaram a estruturação de uma ferramenta que contempla os critérios essenciais para a segurança de puérperas e recém-nascidos, 


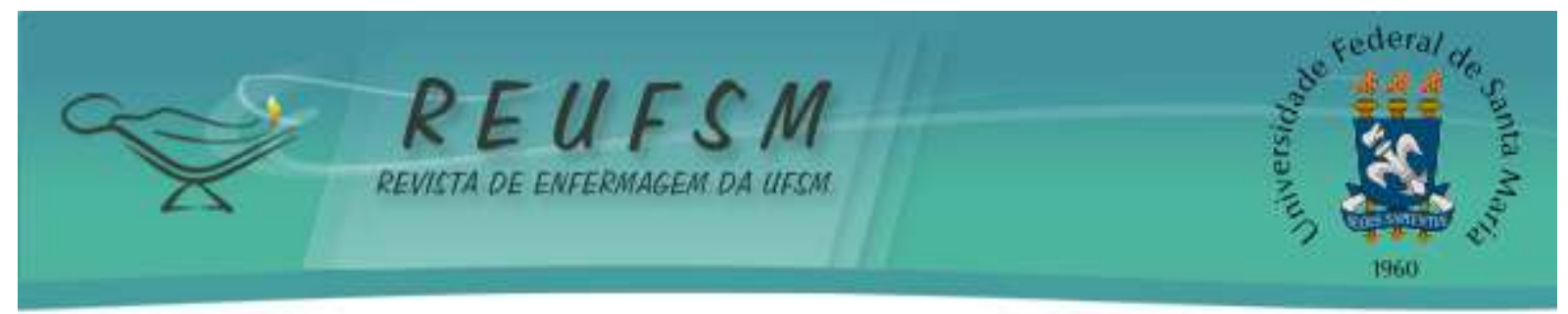

percorrendo as fases do SBAR como referencial teórico, e atendendo as etapas do Arco de Maguerez como método para sua construção.

\section{CONCLUSÃO}

Este estudo identificou que a passagem de plantão realizada atualmente no ambiente hospitalar referido, tem caráter empírico, caracterizado pela ausência de uma ferramenta que possibilite a execução deste processo com qualidade, fragilizando a segurança dos pacientes.

Foram detectados os nós críticos que interferem neste contexto, como o local, as interrupções durante o processo e o excesso de comunicação durante a passagem de plantão. Nesta perspectiva, o instrumento em formato de checklist embasado no modelo SBAR de comunicação e na metodologia ativa do Arco de Maguerez, abordou as caraterísticas necessárias para a passagem de plantão de puérperas e recém-nascidos, na intenção de padronizar e qualificar este processo.

Esta pesquisa apresentou como limitação à incipiência literária internacional e nacional que aborde o modelo SBAR de comunicação na realidade da passagem de plantão em ambiente hospitalar. Em suma, a passagem de plantão do enfermeiro se configura como um processo que influencia na segurança dos pacientes quando viabilizado por ferramentas de gestão que organizem esta prática.

\section{REFERÊNCIAS}

1. Silva MF, Anders JC, Rocha PK, Souza AIJ, Burciaga VB. Comunicação na passagem de plantão de enfermagem: segurança do paciente pediátrico. Texto \& Contexto Enferm [Internet]. 2016 [acesso em02017 jul 4];15(3):e3600015. Disponível em: http://www.scielo.br/pdf/tce/v25n3/pt_0104-0707-tce-25-03-3600015.pdf.

2. Brasil. Agência Nacional de Vigilância Sanitária. Segurança do paciente e qualidade em serviços de saúde: uma reflexão teórica aplicada à prática. Brasília (DF): ANVISA; 2013.

3. Martin HA, Ciurzynski SM. Situation, background, assessment and recommendationguided huddles improve communication and teamwork in the emergency department. Int Emerg Nurs [Internet]. 2015 [acesso em 2017 jul 5];41(6):484-8. Disponivel em: http://www.jenonline.org/article/S0099-1767(15)00228-7/fulltext.

4. Silva MF, Anders JC, Rocha PK, Souza AI, Burciaga VB. Comunicação na passagem de plantão de enfermagem: segurança do paciente pediátrico. Texto \& Contexto Enferm [Internet] 2016 [acesso em 2017 jul 5];25(3):1-9. Disponível em: http://www.scielo.br/pdf/tce/v25n3/pt_0104-0707-tce-25-03-3600015.pdf. 


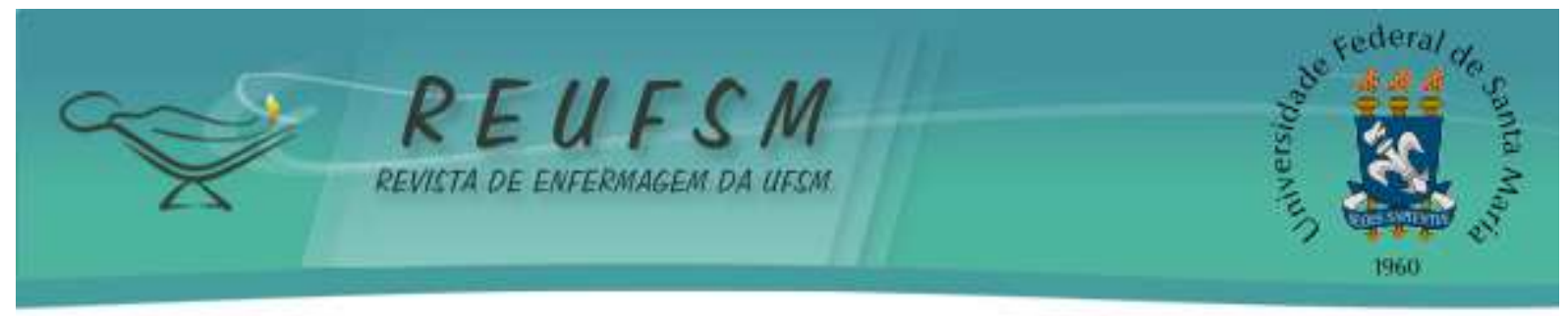

5. Pedro DF, Nicola AL, Oliveira JL. Passagem de plantão entre profissionais de enfermagem hospitalares: análise de fatores influentes. Rev UNINGÁ [Internet]. 2016 [acesso em 2017 jul 6];25(1):27-31.

Disponível

em:

http://www.mastereditora.com.br/periodico/20160102_215634.pdf

6. Holly C, Poletick EB. A systematic review on the transfer of information during nurse transitions in care. J Clin Nurs [Internet]. 2014 [acesso em 2017 jul 4].;23(17-18):2387-95. https://www.ncbi.nlm.nih.gov/pubmed/23786673.

7. Institute for Healthcare Improvement. SBAR Toolkit [Internet]. California: IHI; 2011 [acesso em 2017 jul 5]. Disponivel em: http://www.ihi.org/knowledge/Pages/Tools/SBARToolkit.aspx.

8. Renz SM, Boltz MP, Wagner LM, Capezuti EA, Lawrence TE. Examining the feasibility and utility of an SBAR protocol in long-term care. Geriatr Nurs [Internet]. 2013 [acesso em 2017 jul 5];34(4):259-301. 2013. Disponivel em: https://www.ncbi.nlm.nih.gov/pmc/articles/PMC3932321/?tool=pubmed.

9. Burger D, Jordan S, Kyriacos U. Validation of a modified early warning score-linked Situation-Background-Assessment-Recommendation communication tool: A mixed methods study. J Clin Nurs [Internet]. 2017 [acesso em 2017 jul 5]. Disponivel em: https://www.ncbi.nlm.nih.gov/pubmed/28401657.

10. Birmingham P, Buffum MD, Blegen MA, Lyndon A. Handoffs and patient safety: grasping the story and painting a full picture. West J Nurs Res [Internet]. 2015 [acesso em 2017 jul 5];37(11):1458-78. Disponível em: https://www.ncbi.nlm.nih.gov/pubmed/24951369.

11. Panesar R, Albert B, Messina C, Parker M. The effect of an electronic SBAR communication tool on documentation of acute events in the pediatric Intensive Care Unit. Am J Med Qual [Internet]. 2016 [acesso em 2017 jul 5];31(1):64-8. Disponível em: https://www.ncbi.nlm.nih.gov/pubmed/25274104.

12. Minayo MC. O desafio do conhecimento: pesquisa qualitativa em saúde. $13^{a}$ ed. São Paulo: Hrecitec; 2013.

13. Abib G, Hoppen N, Hayashi Jr P. Observação participante em estudos de administração da informação no Brasil. Rev Latinoam Enferm. 2012;53(6):604-16.

14. Silva Júnior JN, Barbosa FG, Mafezoli J, Lima MA. Utilização do arco de maguerez modificado como uma metodologia problematizadora na síntese da p-nitroacetanilida. Rev Virtual Quim [Internet]. 2014 [acesso em 2017 jul 5];6(4):978-88. Disponível em: http://rvq.sbq.org.br/imagebank/pdf/v6n4a12.pdf.

15. Raymond M, Harrison MC. The structured communication tool SBAR (Situation, Background, Assessment and Recommendation) improves communication in neonatology. S AfrMed J [Internet]. 2014 [acesso em 2017 jul 5];104(12):850-2. Disponível em: http://www.scielo.org.za/scielo.php?script=sci_arttext\&pid=S0256-

95742014001200011\&lng=en\&nrm=iso. 


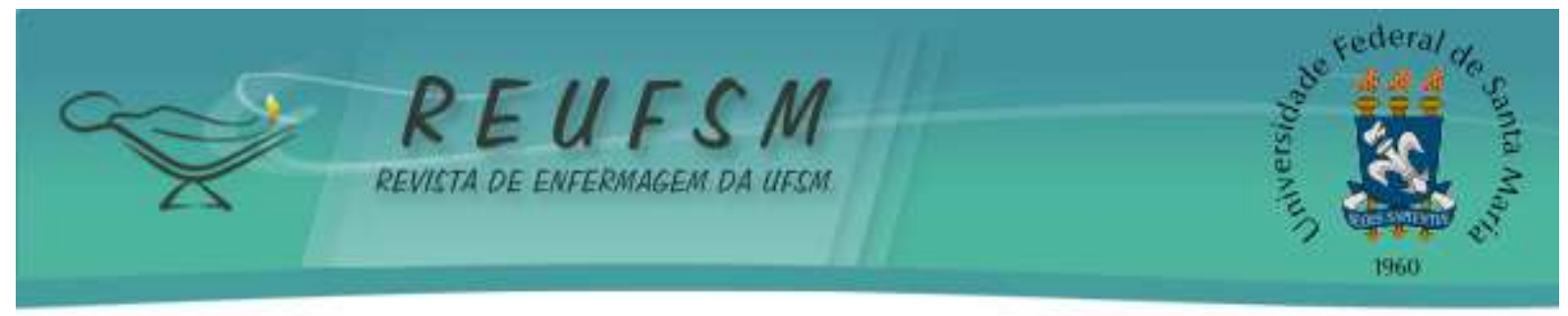

16. Kostoff M, Burkhardt C, Winter A, Shrader S. An interprofessional simulation using the SBAR communication tool. Am J Pharm Educ [Internet]. 2016 [acesso em 2017 jul 5];80(9):157. Disponível em: https://www.ncbi.nlm.nih.gov/pmc/articles/PMC5221839/.

17. Bueno BR, Moraes SS, Suzuki K, Gonçalves FA, Barreto RA, Gebrim CF. Characterization of handover from the surgical center to the intensive care unit. Cogitare Enferm. 2015;20(3):512-8.

18. Silva SF, Cruz IC. Shift changes the bedside (health staff and family): sistematic literature review for a clinical protocol. Jornal of Specialized Nursing Care [Internet]. 2016 [acesso em 2017 jul 5];8(1). Disponível em: http://www.uff.br/jsncare/index.php/jsncare/article/view/2841/698.

19. Oliveira MC, Rocha RG. Reflexão acerca da passagem de plantão: implicações na continuidade da assistência de enfermagem. Enferm Rev. 2016;19(2):226-33.

20. Valera IM, Reis GA, Oliveira JL, Souza VS, Hayakawa LY, Matsuda LM. Passagem de Plantão em Unidades de Terapia Intensiva Pediátrica: estudo descritivo. Online Braz J Nurs. [Internet] 2015 [acesso em 2017 jul 5];14:440-2. Disponível em: http://www.objnursing.uff.br/index.php/nursing/article/view/5281/html_932.

21. Llapa Rodriguez EO, Oliveira CS, França TRS, Andrade JS, Campos MPA, Silva FJCP. Programación del cambio de turno desde la óptica de los profesionales de enfermeira. Enfermería Global [Internet]. 2013 [acesso em 2017 jul 5];12(31):206-18. Disponível em: https://digitum.um.es/xmlui/handle/10201/35676.

22. Correia CQ, Mendonça AE, Souza NL. Produção cientifica sobre ruídos na unidade de terapia intensiva neonatal: revisão integrativa. Rev Enferm UEPE [Internet]. 2014 [acesso em 2017 jul 5];8(1):2406-12. Disponível em: https://periodicos.ufpe.br/revistas/revistaenfermagem/article/viewFile/9932/10228.

23. Gonçalves MI, Rocha PK, Souza S, Tomazoni A, Dal Paz BP, Souza AIJ. Segurança do paciente e passagem de plantão em unidades de cuidados intensivos neonatais. Rev Baiana Enferm [Internet]. 2017 [acesso em 2017 jul 5];31(2):e17053. Disponível em: https://portalseer.ufba.br/index.php/enfermagem/article/view/17053/14606.

24. Silva SG, Nascimento ERP, Hermida PMV, Sena AC, Klein TCR, Pinho FM. Checklist para passagem de plantão de pacientes em pós-operatório imediato na admissão em terapia intensiva. Enferm Foco. 2016;7(1):13-7.

25. Fujita JA, Carmona EV, Shimo AK, Mecena EH. Uso da metodologia da problematização com o Arco de Maguerez no ensino sobre brinquedo terapêutico. Rev Port Educação. 2016;29(1):229-58.

Data de submissão: 04/10/2017

Data de aceite: 14/05/2018

Autor correspondente: Juliana da Silva Garcia Nascimento

E-mail: mestradounesp@yahoo.com.br

Endereço: Rua Osório Joaquim Guimarães, nº 281, Ap. 203, Bloco 05, Parque São Geraldo, Uberaba, Minas Gerais.

CEP: 38030130 